\title{
The Essential Issues of the ESP Classroom from a Reflective View
}

\author{
Wenjie Shi ${ }^{1}$ \\ ${ }^{1}$ School of Foreign Studies, the Central University of Finance and Economics, China \\ Correspondence: Wenjie Shi, School of Foreign Studies, the Central University of Finance and Economics, China. \\ E-mail: wenjieshi@cufe.edu.cn
}

Received: April 6, 2018 Accepted: May 9, 2018 Online Published: May 11, 2018

doi: 10.5539/elt.v11n6p16 URL: http://doi.org/10.5539/elt.v11n6p16

\begin{abstract}
The study looks at the three essential issues concerning the ESP classroom, the practitioners, teaching materials and testing tools, by reflecting on the publications of the ESP classroom three decades earlier and examining the current developments in China. First, in response to the demographic changes in the ESP practitioners and the inter-disciplinary feature of the ESP classroom, collaborative involvement of practitioners from language teachers, subject teachers of specific disciplines and professionals in the workplace was recommended. Second, with regards to teaching materials and methodology design in the ESP classroom, classroom activities based on learners' needs and ways of teaching suited to prospective functions were proposed, which can be achieved by joint efforts of practitioners through in-class teaching and in-field coaching. Third, the ESP related course evaluation and student assessment at different levels were discussed, arriving at the conclusion that, beside international ESP/EAP tests, localized and specified tests that are constructed on the basis of proper balance of language knowledge and subject knowledge need to be addressed and adopted in the ESP classroom.
\end{abstract}

Keywords: assessment, English for Specific Purposes, material design, instruction

\section{Introduction}

One of the earlier publications, The ESP Classroom was published in 1984 in the following of the forth biennial conference of the SELMOUS (Special English Language Materials for Overseas University Students), which was organized in 1983 to look at the issues of English for Academic Purposes and Specific Purposes in the context of UK tertiary educational institutions. The SELMOU was replaced by The British Association of Lecturers in English for Academic Purposes in 1989, and then by BALEAP in 2010 (About BALEAP), which has been consistently devoted to the EAP/ESP teaching and learning as an active institution.

The theme for the seminar in 1983 co-organized with The University of Exeter was: The ESP Classroom: methodology, materials, expectations, thereby an array of topics in the classroom were covered in the special volume for the meeting.

Practicality is one feature of the issues and solutions addressed by the conference. The papers published in the volume cover wide range of issues of practical concern: challenges and prospects for the ESP and EAP, need analysis and case studies of teaching English for science, business and economics purposes, the ESP instruction and assessment methods adopted by these teachers in learner-centered approach. The authors of the papers that were collected in the volume shared their confusion and creative explorations in the ESP and EAP instruction, without using sophisticated modeling of statistics, fancy diagrams or visually dazzling charts. Instead, fluid descriptive language and clear writing logic were demonstrated by the contributors who were primarily lecturers driven by innovative ideas in the ESP theoretical and practical domains, to elaborate on their viewpoints over practical issues from classroom teaching faced by the ESP practitioners in more than three decades ago.

\section{Research Questions}

The pressing issues they mentioned more than thirty years earlier concerning the ESP and EAP practitioners are still with us today, albeit some changes or alterations having been in place within the ambit of these pioneers' prediction.

In this study, we will analyze the following essential issues related to the ESP and EAP from a reflective view:

1) who are the ESP and EAP practitioners?

2) what and how will they teach? 
3) how will they evaluate the course and assess the learners?

As Figure 1 shows, the three research questions are focused on the three essential factors associated with the ESP classroom, namely the practitioners, material design, instruction and assessment, which are placed in an interacting and mutually affecting relation within the ESP classroom. The practitioners will have a decisive influence on the material design and instruction that will lead to the assessment regarding what and how the course contents will be assessed. Similarly, the results of assessment will be taken into consideration by the practitioners, who will subsequently adjust the teaching materials and update the ways of instruction.

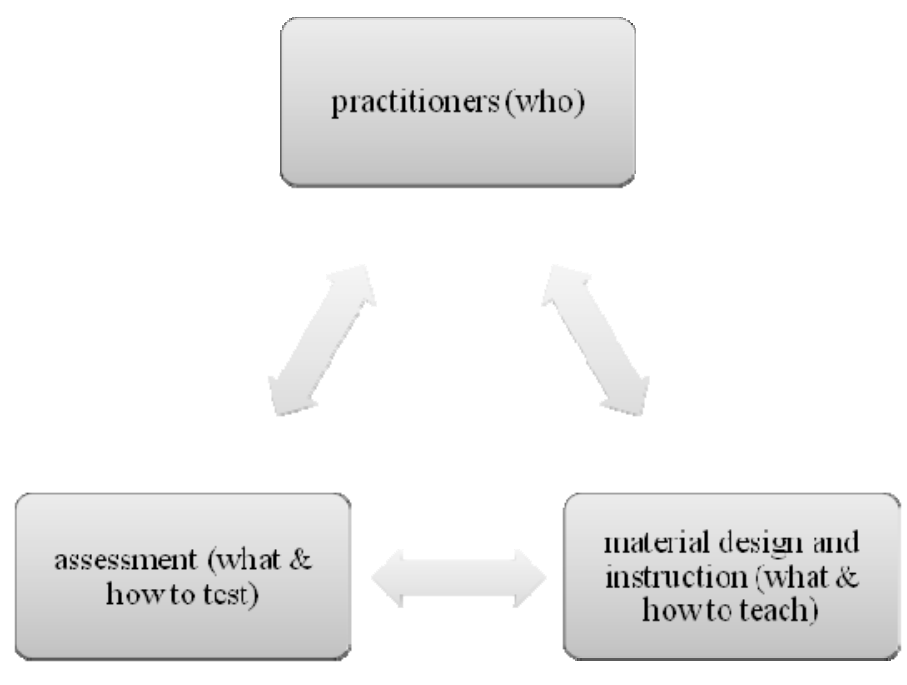

Figure 1. Essential factors of the ESP classroom

\section{Essential Issues of ESP Classroom}

The essential factors illustrated in Figure 1 of ESP classroom remain persistent over the past decades, even though the educational and pedagogical beliefs underpinning the classroom instruction might have gone through some changes which were influenced by other disciplines in which they have specific operations. We will look at the three factors in details from a comparative and reflective perspective.

\subsection{Who Are the Practitioners of ESP and EAP?}

In light of the practitioners' special status of being placed within an inter-disciplinary scenario and marginalized, those forerunners in the ESP and EAP noted the uneasiness imposed on the staff involved, particularly for language teachers. First, the courses of the ESP and EAP, functionally 'Service English' (Swales, 1984) for specific disciplines, had been arguably placed in a peripheral position, which put the ESP practitioners, dubbed as 'Service English staff' (Swales, 1984), in an awkwardly marginalized self-identity in relation to faculty in subject courses of relevance. Second, the ESP practitioners were marginalized on the grounds that the courses were received with less prioritized timetabling in universities, the unstable attendance from students, de-motivating or suspecting attitudes from specific subject teachers and fluctuating staff turnover. Moreover, the challenges posed to the 'Service Department' (Swales, 1984), centers or departments offering language courses, persist with noticeable evidence of diminished service hours, fund shortage and resource inadequacy on a global scale. Nevertheless, over the past decades, it needs to be admitted that the EAP courses in the UK higher education institutions indeed have helped overseas students academically adapt themselves to the rules of games in English language dominant academia.

Likewise, the ESP practitioners are faced with the similar challenges in China's tertiary educational institutions (Cheng, 2016), where a nationwide transformation from the EGP (English for General Purposes) to ESP and EAP is underway, with service hours allocated to compulsory college English course for undergraduates being slashed (Cai, 2012; Shi, 2018), language teachers being placed in a status of periphery. The nationwide reform in English education was based on the assumption that English was previously over-prioritized, but failed to live up to the expectations of educational authority and other stakeholders, like employers who need staff with English language expertise and EFL learners who may not want English language skills so eagerly. Consequently, this 
overhaul will generate impact to EFL learners as well as teachers with regard to learner needs, teaching contents and self identity of teachers (Cai, 2015; Wang, 2015; Tao \& Guo, 2018), whereas the efficaciousness of which remains to be seen. In this case, the ESP and EAP practitioners, preferably discerned as 'educationist-cum-communication experts' (Swales, 1984), need to be self-positing their role and responsibilities in the sense that their service with dedication has been facilitating students and teachers of specific disciplines in their academic pursuit and study, and will always be, either in the status of priority or periphery. In addition, the ESP practitioners can note that the ESP and EAP drew mounting attention from academics and raised recognition across academic and professional domains by more theoretical and practical creation that were produced from array of conferences and seminars around the globe (Cheng \& Anthony, 2014).

In sum, the ESP and EAP pedagogy featured by the inter-disciplinary or inter-departmental engagement necessitates collaborative efforts from 'teaching team' composed of language teachers and specific subject teachers. The forerunners in the ESP teaching who devoted themselves decades ago to improving learning effectiveness appealed to inter-sectional collaboration by regularly exchanging ideas with specific subject teachers, negotiating and co-supervising teaching contents (Jordan, 1984). Therefore, the ESP and EAP practitioners with linguistically academic expertise were expected primarily to assume the role of purveyor for learning materials and orchestrator of acquisition (Swales, 1984), guiding learners with learning methods aided by subject lecturers.

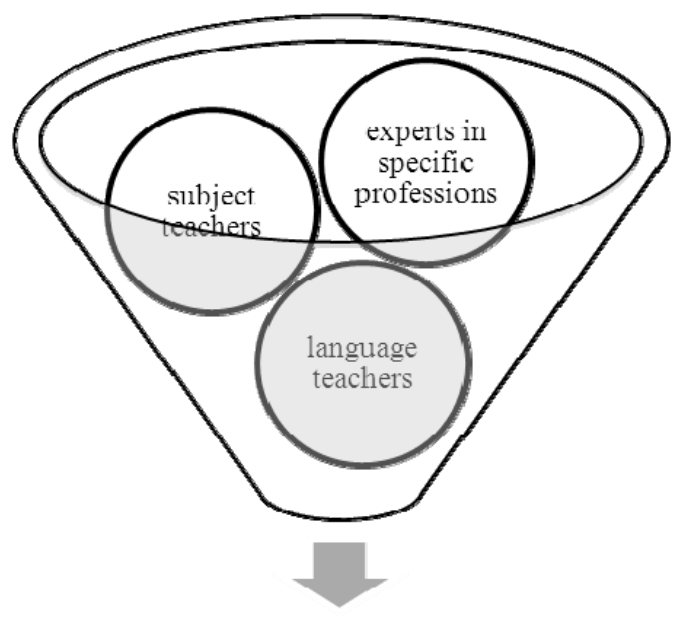

ESP Practitioners

Figure 2. Practitioners in the ESP classroom

Finally, we recommend that the cohort of the ESP practitioners be expanded to specialists in professional fields of business. As Figure 2 indicates, the collaborative engagement between language teachers, subject teachers and professional specialists enables language teachers to know better about students' learning needs and subject teachers' expectations for the ESP courses, and the linguistic features in specific disciplines. In addition, experts in specific professions can also be part of the ESP practitioners in the sense that these professionals of specific expertise are inclined to follow closely the up-to-date developments in their industry and profession, which is likely to contribute to needs survey, course design and teaching methods. As a result, instruction in ESP classrooms will be more likely attuned to specified needs in different disciplines and professions, engendering learning effectiveness to a great magnitude.

\subsection{What and How Will They Teach?}

The course of the ESP remains different from that of the EGP in that the former was devised in response to increasingly diversified and specified learners' needs, which have been regarded as an essential step for generating course materials and syllabi.

There has been a controversy over the level of authenticity of classroom teaching in relation to target language use domains in workplaces, which can be found that the degree to which the 'classroom discourse' interact with the 'target discourse' (Swales, 1984) in course design is conducive to differed learning effectiveness. It was claimed that the authenticity of ESP classroom might bring about over assimilation of classroom instruction to 
business practice, which is likely to de-motivate the ESP learners to some extent (Swales, 1984). However, in the ESP classroom, it is argued that authentic teaching materials based on target language use tasks can be of value in arousing learners' motivation to learn and proactive engagement in classroom activities (Hutchinson \& Waters, 1987). Therefore, when designing courses for the ESP classroom by adopting authentic materials is constrained by physical space and sources, the materials used in ESP classroom need at least to be related to the target language use tasks in workplace. Meanwhile, we need to note that course design of the ESP is subject to a cyclical process that requires continual efforts in needs analysis, which demands practitioners to probe the factual needs in business and industries, as was the case with those innovative researchers and teachers over thirty years ago (Jordan, 1984).

With regard to the teaching methods in the ESP classroom, the pragmatic feature of the ESP entails more field work undertaken by language teachers and learners to the business of specific industries, frequent contacts with experts and professional in different departments of business fields.

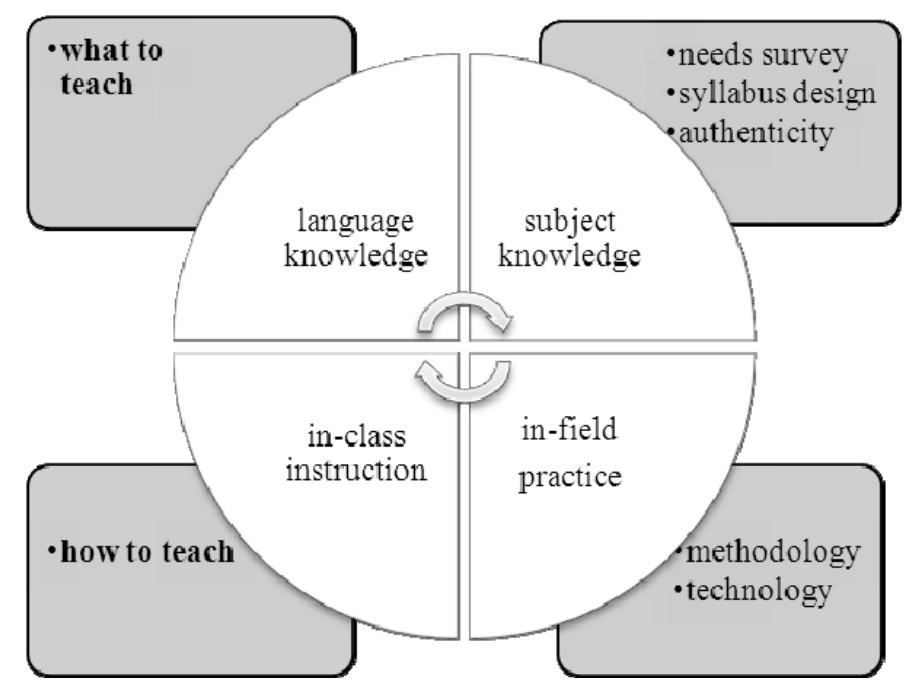

Figure 3. Material design and teaching methods in the ESP classroom

Therefore, as Figure 3 demonstrates, designing the courses of the ESP or EAP by collaborating with experts in these fields of relevance and delivering the courses in conjunction with faculty and staff from disciplines concerned are the issues we are to face in terms of what and how we will teach now and in future.

Furthermore, as the lower part of Figure 3 shows, methodology and technology will be given priority in relation to how to teach. For instance, computer-assisted language learning and instruction emerged to find their way in improving learning and teaching effects more than three decades ago, which was anticipated to generate broader influence on language teaching, learning and testing in the editorial overview of the book. The earlier predictions on these technologies are happening in today's ESP and EAP classroom, where rapidly developing technology arms learners and teachers with huge variety of big-data and the Internet-based soft-wares claiming to boost learning and teaching. Indeed, on one hand, these technologies earmarked by artificial intelligence are redefining the vehicles of learning and knowing for the current language learners, enslaving them via ever-expanding devices and gadgets; on the other hand, these novel teaching trends featured by multi-media interactive learning and teaching have, to a great extent, are reshaping the landscape of understanding and communicating in a cognitive sense. It may be no surprise that one day in the not so far future when less people will make efforts to learn foreign languages because the seemingly omnipresent APPs will help them survive linguistically the settings where foreign languages are required. Conversely, the technologies that make people inactive in their brain activities by liberating people from deciphering the language codes through intense mental efforts are likely to strip people of the mental sensitivity engaged in juggling among several languages. For instance, the wider accessibility to corpus-based machine translation and internet-based AI translation APPs might be discouraging language learners from working hard on foreign languages on the widely accepted assumption that these technologies considerably outperform human brains in terms of code-switching speed and memory volume. 
While technology-assisted language learning and teaching have brought about revolutionary changes to the ways of learning and teaching languages, and undoubtedly will continue to exert impact on this field, nevertheless, the ESP and EAP practitioners are still expected to follow the acquisition process of affective cognition while utilizing modern technologies in their teaching practice.

Another change that took place over the past decades from international perspective is related to the geographic shift of the EAP instruction from the inner-circle English speaking countries to outer-circle and extended-circle English speaking countries or territories, as can be pinpointed by an expanding body of non-native English EAP practitioners who are devoted to the EAP instruction in non-English speaking countries. Therefore, non-native English lecturers in conjunction with native language experts in the domain of the EAP and ESP instruction will be another mode that will shift the locations of the EAP and ESP teaching from English speaking countries to non-native English speaking ones.

In addition, the demographic features of the EAP learners are different from decades ago, when they were mainly learning in the English speaking countries, primarily composed of the EFL learners at postgraduate level for master degrees or above. But now the undergraduate students studying for bachelor degrees constitute the vast majority of the EAP learners, and most of them engage themselves in learning in non-native English speaking countries or territories, as is particularly the case for the current ESP/EAP teaching in China (e. g., Cai, 2015; Cheng, 2016).

Therefore, non-native English speaking EAP or ESP teachers in collaboration with native English counterparts give instruction to learners at their younger ages in non-English speaking territories will be novel developments in the ways of the EAP and ESP teaching.

\subsection{How Will They Evaluate the Course and Assess the Students?}

Evaluation and assessment are usually a neglected aspect with consistently less academic attention for the ESP and EAP research, which was identified more than 30 years ago (James, 1984) and invariably remains an issues of being insufficiently addressed by academics in today's global research context (Hamp-Lyons, 2011; Schmitt \& Hamp-Lyons, 2015). It was argued that an urgent need for reliable proficiency tests to identify and assess students learning needs has not been fulfilled decades ago when the EAP and ESP assessment was in the beginning phase. Now we seem to have more options available for the EAP or ESP tests. Nevertheless, the fact that we are currently accessible to more options of large scale internationalized language tests in EAP (e. g., IELTS Academic, TOEFL, Pearson English Test Academic) and ESP (e. g., BEC, BULAST, TOIEC, etc.) that seem fairly attested to be based on well-devised and technically validated language testing theories and practices by no means indicates that there is no need for localized and subject specific EAP or ESP assessments.

Theoretically, the ESP practitioners are assuming multiple roles that consist of course evaluator and learner assessor, which required the language teachers to update themselves with the essential competence and knowledge of language assessment in general and the ESP and EAP assessment in particular (Schmitt \& Hamp-Lyons, 2015).

Pedagogically, to devise an EAP and ESP course evaluation framework to assess the degree to which the courses have achieved effective outcome in meeting the learning outcomes and securing teaching objectives will remain an issue of wide concern. Meanwhile, the EAP and ESP based learner assessments constructed to provide indicative evidence for the credibility of the specific courses will be worthy of attention. As Figure 4 shows, learner assessment and course evaluation in the ESP classroom are of no fundamental difference from those of English for General Purposes, which are measured by the tools of assessment and evaluation that are composed of international and local levels. However, one of the key issues for assessment and evaluation in the ESP is the construct to be assessed or evaluated by these tools, in which the appropriate balance of language and subject knowledge has been drawing academic attention. 


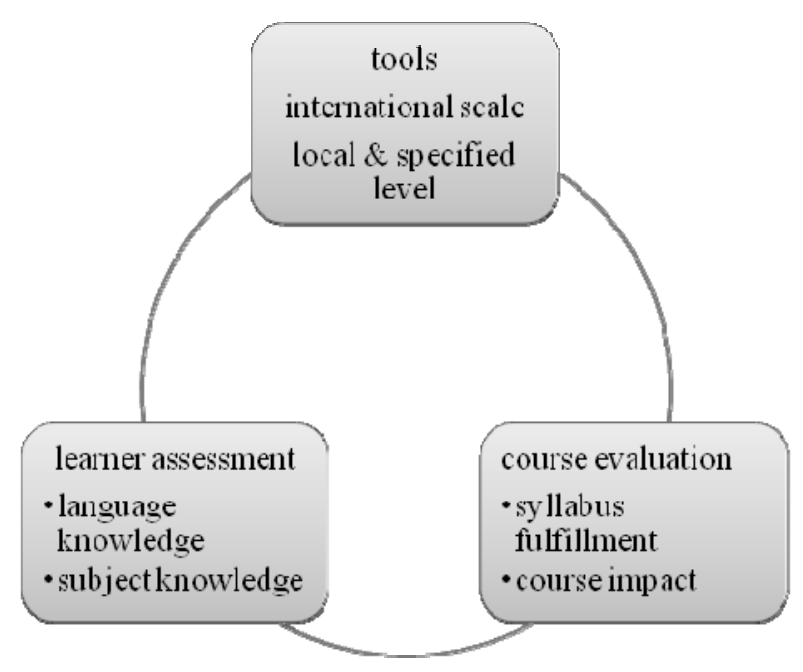

Figure 4. Assessment and evaluation in the ESP classroom

Furthermore, the construct for the EAP and ESP assessment remains under-defined and under-represented in assessment literature (Schmitt and Hamp-Lyons, 2015), which needs to be more specifically studied on the basis of wide range of specified language courses in order to develop the tests constructed with more accurate representatives, typically represented by the local or specified assessment tools illustrated in Figure 4.

With regard to course evaluation, Figure 4 indicates that syllabus fulfillment and course impact that can be measured by end-of-course surveys on learners' behavior and motivation will give reliable indication over the effectiveness of the ESP courses.

Finally, if the first stage of the ESP was mainly focused on material design based on needs, the second stage is primarily concerned about the approaches of classroom teaching, the pedagogical issues. It can be argued that we are in the stage of going global for the ESP and EAP teaching and assessing, which can be illustrated by the fact that growing number of institutions in different countries or territories are on the way of devising localized and more discipline-specific ESP and EAP courses and assessment, as is particularly true for East Asia (Cheng \& Curits, 2010).

\section{Conclusion}

By examining the essential issues related to the ESP Classroom from reflecting on those classical publications that started being circulated over three decades earlier and exploring the latest developments in China, we are ensured that the evolution of ESP instruction in terms of material development, teaching and research methods, publication accessibility and cross-border communications has placed ESP's prominence into wider academic concern.

Meanwhile, with admiration to those forerunners in this domain who blazed the trails of ESP instruction and assessment we can argue that modern practitioners are still badly in need of the dedication and pioneering spirits manifested by earlier practitioners, in an attempt to handle the persistent and fundamental issues in the ESP domain in an rapidly changing ESP classroom.

In sum, the scope of the ESP practitioners should be more inclusive, the teaching materials and methodologies need to take account of the demographic and geographic changes that happened to the ESP classroom on a global scale. Evaluation and assessment will be a field full of research opportunities.

\section{Acknowledgement}

This study is part of the research findings from the project entitled The Study of ESP Instruction and Assessment for Universities of Finance and Economics in the Context of a New College English Program sponsored by the Central University of Finance and Economics to whom I extend my thanks.

\section{References}

About BALEAP. Retrieved April 9, 2018, from https://www.baleap.org/about-baleap/about-us

About the TOEFL iBT ${ }^{\circledR}$ Test. Retrieved April 9, 2018, from https://www.ets.org/toefl/ibt/about 
Cai, J. (2012) A way out for EFL at tertiary level education in Mainland China. Shanghai: Shanghai Jiaotong University Press.

Cai, J. (2015). ESP education development in China: Retrospect, problems and tasks. Journal of Xi'an International Studies University, 23(1), 68-72.

Cheng, A. (2016). EAP at the tertiary level in China: Challenges and possibilities. In K. Hyland, \& P. Shaw (Eds.), The Routledge handbook of English for academic purposes (pp. 97-108). New York: Routledge.

Cheng, A., \& Anthony, L. (2014). ESP research in Asia: Guest editorial. English for Specific Purposes, 33, 1-3. https://doi.org/10.1016/j.esp.2013.07.002

Cheng, L., \& Curits, A. (Eds.). (2010). English language assessment and the Chinese learner. New York: Routledge: Taylor's \& Francis Group.

Hamp-Lyons, L. (2011). English for academic purposes. In E. Hinkel (Ed.), Handbook of research in second language testing and learning (Vol. 2, pp. 89-105). New York, NY: Routledge. https://doi.org/10.1016/j.jeap.2011.01.001

Hutchinson T., \& Waters A. (1987). English for Specific Purposes-A learning-centered approach. Cambridge: Cambridge University Press. https://doi.org/10.1017/CBO9780511733031

IELTS for study. Retrieved April 9, 2018, from https://www.ielts.org/what-is-ielts/ielts-for-study

Jordan, R. R. (1984). Motivation in ESP: a case study of methods and materials for Economics. In G. James (Ed.) The ESP classroom: methodology, materials, expectations. Exeter Linguistic Studies (Volume 7, pp. 82-88). UK: A. Wheaton \& Co. Ltd., Exeter.

Schmitt, D., \& Hamp-Lyons, L. (2015). The need for EAP teacher knowledge in assessment. Journal of English for Academic Purposes, 18, 3-8. https://doi.org/10.1016/j.jeap.2015.04.003

Shi, W. (2018) Exploring course design for a university-level ESP- based College English Program in University of Finance and Economics in China. Journal of Teaching English for Specific and Academic Purposes, 6(1), 115-124. https://doi.org/10.22190/JTESAP1801115S

Swales, J. (1984). Thoughts on, in and outside the ESP classroom. In G. James (Ed.) The ESP classroom: methodology, materials, expectations. Exeter Linguistic Studies (Volume 7, pp. 7-16). UK: A. Wheaton \& Co. Ltd., Exeter.

Tao, J. T., \& Gao, X. A. (2018). Identity constructions of ESP teachers in a Chinese university. English for Specific Purposes, 49, 1-13. https://doi.org/10.1016/j.esp.2017.09.003

Wang, W. (2015). Teaching English as an international language in China: Investigating Chinese university teachers' and learners' attitude towards China English. System, 53, 60-72. https://doi.org/10.1016/j.system.2015.06.008

Why PTE Academic? Retrieved April 9, 2018, from https://pearsonpte.com/why-pte-academic/

\section{Copyrights}

Copyright for this article is retained by the author(s), with first publication rights granted to the journal.

This is an open-access article distributed under the terms and conditions of the Creative Commons Attribution license (http://creativecommons.org/licenses/by/4.0/). 